\title{
PERFIL DE SENSIBILIDADE A ANTIMICROBIANOS POR COMPONENTES DA MICROBIOTA BACTERIANA ORAL E RETAL DE PRIMATAS NÃO HUMANOS
}

\author{
ANTIMICROBIAL SENSITIVITY PROFILE BY COMPONENTS OF \\ BACTERIAL ORAL AND RETAL MICROBIOTA OF NON-HUMAN PRIMATES
}

\author{
Marcone Helmer Silva ${ }^{1^{*}}-$ ORCID http://orcid.org/0000-0002-6050-4839 \\ Hilma Lúcia Tavares Dias ${ }^{2}$ - ORCID http://orcid.org/0000-0002-9121-3065 \\ Ednaldo da Silva Filho ${ }^{3}$ - ORCID http://orcid.org/0000-0002-8009-3504 \\ Sarah Raphaela Rocha de Azevedo Scalercio ${ }^{1}$ - ORCID http://orcid.org/0000-0002-2681-0736 \\ Wellington Bandeira da Silva1 - ORCID http://orcid.org/0000-0001-8057-0836 \\ Roberto de Farias Espinheiro² - ORCID http://orcid.org/0000-0002-6786-1708 \\ ${ }^{1}$ Centro Nacional de Primatas, Ananindeua, PA, Brasil. \\ Universidade Federal do Pará, Belém, PA, Brasil. \\ 3Universidade Federal Rural da Amazônia, Belém, PA, Brasil. \\ "Autor para correspondência - helmerseemp@gmail.com
}

\section{Resumo}

Os objetivos desta pesquisa foram identificar bactérias isoladas da cavidade oral e da ampola retal de Saimiri collinsi e Callithrix jacchus e determinar a sensibilidade a 16 antimicrobianos. Trinta indivíduos de cada espécie foram analisados e foram isoladas 136 bactérias em C. jacchus e 84 em S. collinsi. As bactérias isoladas em maior número em $S$. collinsi foram Klebsiella pneumoniae, Escherichia coli, Enterobacter cloacae, Raoutella ornithinolytica, Staphylococcus xylosus e Proteus mirabilis. As bactérias isoladas em C. jacchus foram K. pneumoniae, E. cloacae, E. coli, Serratia marcescens e $S$. xylosus na cavidade oral e ampola retal. O teste de sensibilidade mostrou que, dentre as cepas isoladas, os maiores percentuais de resistência foram observados para ampicilina, amoxicilina, cefalotina e nitrofurantoína. $\mathrm{Na}$ cavidade oral de ambas as espécies as cepas foram sensíveis à ceftazidima, ceftriaxona, meropenem, amicacina, levofloxacina e a sulfametoxazol/ trimetoprim. Na ampola retal, as isoladas foram sensíveis à cefoxitina, ceftazidima, ceftriaxona, ertapenem, meropenem, amicacina e levofloxacina. Conclui-se que as espécies de $S$. collinsi e $C$. jacchus apresentam sua microbiota oral e retal composta por várias espécies bacterianas e que a resistência pode ser um problema no criatório, uma vez que as cepas mostraram percentuais elevados de resistência a diferentes antimicrobianos.

Palavras-chave: Microbiologia, Callithrix jacchus, Saimiri collinsi, Amazônia, Antibióticos.

\begin{abstract}
The aims of this work were to identify bacteria isolated from oral cavity and rectal ampoule in the Saimiri collinsi and Callithrix jacchus species and to determine the susceptibility profile to 16 anti-microbial. Thirty individuals of each species were analyzed and were isolated 136 bacteria in C. jacchus and 84 in S. collinsi. The isolated bacteria most frequent in S. collinsi were Klebsiella pneumoniae, Escherichia coli, Enterobacter cloacae, Raoutella ornithinolytica, Staphylococcus
\end{abstract}


xylosus and Proteus mirabilis. The bacteria isolated in C. jacchus were K. pneumoniae, E. cloacae, E. coli, Serratia marcescens and S. xylosus in oral cavity and rectal ampoule. Results of sensibility tests demonstrated that among isolated strains from oral cavity and rectal ampoule the highest percentages of resistance were observed against ampicilin, amoxicilin, cephalothin and nitrofurantoin. The oral cavity in both species, the strains were sensitive to ceftazidime, ceftriaxone, meropenem, amikacin, levofloxacin and sulfamethoxazole/trimethoprim. In rectal ampoule the isolates were sensitive to cefoxitin, ceftazidime, ceftriaxone, ertapenem, meropenem, amikacin and levofloxacin. Therefore, in $S$. collinsi e $C$. jacchus presented in their oral and rectal microbiota constituted by several bacteria species and that resistance may be a problem on captive, since that strains demonstrated high percentages of resistance to different anti-microbial.

Keywords: Microbiology, Callithrix jacchus, Saimiri collinsi, Amazon, Antibiotics.

Recebido em 30 de junho de 2017.

Aceito em 20 de fevereiro de 2019.

\section{Introdução}

No reino animal, os primatas não humanos (PNH), devido à similaridade filogenética com a espécie Homo sapiens $^{(1)}$, tornaram-se excelentes modelos experimentais utilizados em pesquisas biomédicas ${ }^{(2)}$. Esses animais são geralmente os melhores ou, às vezes, os únicos modelos para estudar determinadas doenças em humanos, bem como para a elaboração de estratégias de prevenção e terapias ${ }^{(1)}$.

A microbiota refere-se à população de microrganismos (bactérias, vírus, protozoários e fungos) que habitam a pele e as mucosas do corpo humano ou animal, mantendo uma relação de homeostase ${ }^{(3)}$. Ela é determinada por fatores como raça, idade, hormônios, dieta, estresse, comportamento sexual, medicação, sazonalidade reprodutiva, localização geográfica, densidade populacional, contato animal e procedimentos de higiene ${ }^{(4)}$.

A importância do conhecimento da constituição da microbiota em PNH criados em cativeiro está na prevenção de possíveis infecções e complicações clínicas. O contato direto entre o animal e o ser humano parece ser, então, um dos fatores de risco para o aparecimento de animais colonizados por patógenos, sendo que essa colonização não significa necessariamente doença ${ }^{(5)}$.

A microbiota residente em mamíferos é estabelecida pela interação entre o hospedeiro e o meio ambiente $^{(6)}$. Além disso, as interações hospedeiro-microrganismo podem ser comensais, mutualísticas, patogênicas ou parasitárias, e essas interações são conhecidas por influenciar o metabolismo, desenvolvimento e o estado imunológico dos animais ${ }^{(7)}$.

Em PNH saudáveis, as bactérias são encontradas principalmente na mucosa oral, fossas nasais e pele ${ }^{(8)}$, podendo, a partir desses locais, alcançar outras regiões da pele e mucosas, ou produzir infecção local, quando as barreiras naturais estão comprometidas por trauma ou cirurgia ${ }^{(9)}$. Contudo, a composição da microbiota bacteriana de PNH ainda é pouco conhecida ${ }^{(10)}$.

Neste trabalho, objetivou-se isolar e identificar as bactérias presentes na cavidade oral e na ampola retal de PNH sadios das espécies Saimiri collinsi e Callithrix jacchus, criados em cativeiro no Centro Nacional de Primatas na Amazônia Oriental, e testar sua suscetibilidade aos antibióticos. 


\section{Material e Métodos}

Todos os procedimentos experimentais foram submetidos e aprovados pela Comissão de Ética no Uso de Animais (CEUA/IEC) do Instituto Evandro Chagas, sob o protocolo $n^{\circ}$ 07/2016, e seguiram todas as orientações contidas na resolução ${ }^{\circ} 1$, de 9 de julho de 2010 do Conselho Nacional de Controle de Experimentação Animal/Ministério da Ciência e Tecnologia (CONCEA-MCT). Quanto aos aspectos de biossegurança, os profissionais envolvidos utilizaram os equipamentos de proteção individual e coletiva pertinentes, seguindo os procedimentos operacionais da instituição.

O estudo foi realizado dentro das instalações físicas do Centro Nacional de Primatas (CENP-SVS): Seção de Laboratório (SALAB) e Serviço de Ecologia e Manejo de Primatas (SEEMP), localizado às margens da rodovia BR-316, Km 7, no município de Ananindeua, região Metropolitana de Belém Pará - Brasil (1²2’33’S/ 48²2’33” W).

Os animais selecionados pertencem ao plantel reprodutivo do CENP e, durante a execução do experimento, permaneceram sob as mesmas condições de cativeiro nos galpões, ou seja, em recintos de alvenaria revestidos com lajotas $(3,85 \times 2,00 \times 2,40 \mathrm{~m})$, tela de aço, poleiros de cano e madeira, cama com $20 \mathrm{~cm}$ de maravalha (raspas de madeira) autoclavada e agrupados em uma média de cinco animais por recinto. A higienização biológica dos recintos era realizada diariamente com a retirada das fezes e restos de alimentos depositados sob a cama de maravalha e poleiros. A sanitização das instalações e equipamentos era realizada duas vezes por semana (a cada 15 dias), com a retirada da maravalha e lavagem das paredes e poleiros, com sabão, hipoclorito de sódio a 3\% e amônia quaternária, conforme as regulamentações prescritas nos procedimentos operacionais padronizados (POPs) e medidas de biossegurança estabelecidas pela instituição.

No presente estudo foram analisados $60 \mathrm{PNH}$, clinicamente sadios, sendo 30 animais da espécie Saimiri collinsi (15 machos e 15 fêmeas) e 30 Callithrix jacchus (15 machos e 15 fêmeas), pertencentes a duas faixas etárias (juvenil - até 2 anos e adulto - acima de 2 anos). Todos os animais estavam sujeitos ao fotoperíodo natural e recebiam alimentação diária balanceada, à base de hortifrutigranjeiros, ração peletizada específica para primatas neotropicais (MEGAZOO® P18, Proteína 18\%, Fibra Máx. 6,5\%, Betim - MG), suplementos vitamínicos, minerais e água ad libitum.

As colheitas das amostras foram realizadas nos recintos dos animais, enquanto eles eram contidos fisicamente com auxílio de um puçá e luvas de raspa de couro. Para minimizar o estresse e resguardar o bem-estar dos animais, foram monitoradas a frequência respiratória (FR) e a frequência cardíaca (FC). Durante a colheita das amostras havia sempre a presença de, pelo menos, um médico veterinário para a verificação do estado de saúde do animal manipulado, sendo que cada animal possuía uma ficha individual para registro dos dados.

Foram utilizados swabs estéreis para as colheitas de ambas as cavidades, que eram imediatamente encaminhadas ao laboratório de Microbiologia do CENP para realização das análises bacteriológicas.

$\mathrm{O}$ isolamento bacteriano da cavidade oral e ampola retal foi realizado com as amostras semeadas em meio de Ágar Base Sangue (Difco ${ }^{\circledR}$ ) contidas em placas de Petri enriquecidas com 5\% (v/v) de sangue desfibrinado de ovino e Ágar MacConkey (Difco ${ }^{\circledR}$ ), sendo incubadas à temperatura de $37{ }^{\circ} \mathrm{C}$ em intervalo de tempo de 24 até 72 horas. Além disso, para as amostras oriundas da ampola retal, foi realizada a semeadura em Agar Salmonella-Shigella (SS) em placas de Petri, incubadas a $37^{\circ} \mathrm{C}$ entre 24 e 72 horas. Para a identificação dos isolados, foram selecionadas colônias que, posteriormente, seguiram para avaliação das características morfotintoriais. De acordo com esse resultado, foram 
realizados testes de oxidase e catalase.

Adicionalmente, as colônias obtidas das amostras oriundas das cavidades foram repicadas em Ágar Nutriente e, após incubação a $37{ }^{\circ} \mathrm{C}$ durante 24 horas, foram suspensas em $3 \mathrm{~mL}$ de solução salina estéril a 0,45\% e, posteriormente, diluídas até a concentração de 0,53 - 0,63 da escala de MacFarland para a identificação bioquímica pela metodologia automatizada, utilizando o equipamento VITEK Compact II bioMérieux ${ }^{\circledR}$. As identificações foram feitas utilizando-se cartões de identificação: GPI CardbioMérieux ${ }^{\circledR}$ (Gram positive identification) para Gram positivos e GNI CardbioMérieux ${ }^{\circledR}$ (Gram negative identification) para Gram negativos.

Cada cartão de identificação contém 30 substratos bioquímicos liofilizados, que foram reidratados com suspensão bacteriana contendo $10^{5} \mathrm{UFC} / \mathrm{mL}$, preparadas a partir das colônias de bactérias isoladas das amostras coletadas. Os cartões foram inseridos no equipamento, que faz leitura individual de cada poço a cada 30 minutos através da colorimetria. Analisando as mudanças de coloração, o equipamento define um perfil e os resultados são comparados a perfis bacterianos armazenados em sua memória.

Os testes de sensibilidade antimicrobiana foram realizados utilizando o sistema automatizado VITEK Compact II (bioMérieux ${ }^{\circledR}$ ), através da retirada de 50 a $200 \mu \mathrm{L}$ de inóculos bacterianos da solução previamente preparada para a fase de identificação, seguida de nova diluição em $2,8 \mathrm{~mL}$ de solução salina, a $0,45 \%$, e leitura à escala de MacFarland. Optou-se pelos cartões diagnósticos que contenham os seguintes antibióticos: ampicilina, amoxicilina/ácido clavulânico, cefalotina, cefoxitina, cefotaxima, ceftazidima, ceftriaxona, ertapenem, meropenem, amicacina, gentamicina, ácido nalidíxico, ciprofloxacina, levofloxacina, nitrofurantoína e sulfametoxazol/trimetoprim.

Todos os dados relativos às cepas bacterianas foram tabulados no Microsoft Office Excel 2010, sendo determinados os valores relativos a partir dos valores observados. Foi estimado o índice de Shannon para determinação do grau de biodiversidade bacteriana por local (oral e ampola retal) e por faixa etária (jovens e adultos) através da fórmula abaixo:

$$
H^{\prime}=-\sum_{i=1}^{S} p_{i} \ln p_{i}
$$

Onde $\mathrm{p}_{\mathrm{i}} \mathrm{e}$ a frequência relativa de cada cepa bacteriana e $\ln \mathrm{p}_{\mathrm{i}}$ é o logarítimo neperiano das frequências relativas de cada cepa. Os antibiogramas foram descritos na forma de gráficos, referindo às frequências relativas de cepas resistentes, intermediárias e sensíveis, de acordo com os gêneros mais relevantes (maior frequência de isolamento) entre as bactérias orais e retais.

\section{Resultados}

Um total de 220 cepas bacterianas foram identificadas, sendo 84 cepas na espécie $S$. collinsi e 136 na espécie $C$.jacchus. O percentual de isolamentos foi maior na ampola retal em ambas as espécies, com predomínio de bactérias Gram-negativas.

Na cavidade oral de $S$. collinsi juvenis foi observada uma maior frequência de Klebsiella pneumoniae (50\%), Staphylococcus xylosus (30\%), Pseudomonas putida (10\%) e Raoutella ornithinolytica (10\%); e nos adultos prevaleceram $K$. pneumoniae (45\%), R. ornithinolytica (14\%), Enterobacter cloacae 
$(10 \%)$ e Escherichia coli $(10 \%)$.

Com relação às bactérias da ampola retal de animais juvenis, foram identificadas seis espécies com predominância de E. coli (36\%), K. pneumoniae (21\%), E. cloacae (14\%) e Staphylococcus hominis (14\%). Já nos adultos, foram isoladas sete espécies, com destaque para K. pneumoniae (32\%), E. coli (29\%), E. cloacae (13\%) e Proteus mirabilis (13\%). Não foram observadas diferenças no número e na diversidade das espécies bacterianas isoladas de acordo com o sexo.

Na cavidade oral de $S$. collinsi, a diversidade de espécies avaliada pelo Índice de Shannon-Wiener demonstrou diferença na diversidade de espécies bacterianas na variável estudada (juvenil 1,17 e adulto 1,75), sendo maior nos adultos. Já com relação à ampola retal, houve também maior diversidade em adultos (juvenil 1,63 e adulto 1,65), representada na Tabela 1.

Tabela 1. Espécies bacterianas identificadas da cavidade oral e ampola retal de 30 indivíduos da espécie $S$. collinsi mantidos em cativeiro no CENP - Ananindeua/PA

\begin{tabular}{|c|c|c|c|c|c|c|}
\hline \multirow{3}{*}{ Bactérias } & \multicolumn{3}{|c|}{ Cavidade oral } & \multicolumn{3}{|c|}{ Ampola retal } \\
\hline & $\begin{array}{l}\text { Juvenis } \\
\mathbf{n}=\mathbf{9}\end{array}$ & $\begin{array}{l}\text { Adultos } \\
\mathbf{n}=\mathbf{2 1}\end{array}$ & Total & $\begin{array}{c}\text { Juvenis } \\
n=9\end{array}$ & $\begin{array}{c}\text { Adultos } \\
\mathbf{n}=\mathbf{2 1}\end{array}$ & Total \\
\hline & $\mathbf{N}(\%)$ & $\mathbf{N}(\%)$ & $\mathbf{N}(\%)$ & $\mathbf{N}(\%)$ & N (\%) & $\mathbf{N}(\%)$ \\
\hline Aeromonas hydrophila & & $1(3)$ & $1(3)$ & & & \\
\hline Citrobacter amalonaticus & & $1(3)$ & $1(3)$ & & & \\
\hline Citrobacter koseri & & & & & $1(3)$ & $1(2)$ \\
\hline Enterobacter aerogenes & & & & $1(7)$ & $1(3)$ & $2(4)$ \\
\hline Enterobacter cloacae & & $3(10)$ & $3(8)$ & $2(14)$ & $4(13)$ & $6(13)$ \\
\hline Escherichia coli & & $3(10)$ & $3(8)$ & $5(36)$ & $9(29)$ & $14(31)$ \\
\hline Klebsiella oxytoca & & & & $1(7)$ & $2(6)$ & $3(7)$ \\
\hline Klebsiella pneumoniae & $5(50)$ & $13(45)$ & $18(46)$ & $3(21)$ & $10(32)$ & $13(29)$ \\
\hline Pantoea agglomerans & & $2(7)$ & $2(5)$ & & & \\
\hline Proteus mirabilis & & & & & $4(13)$ & $4(9)$ \\
\hline Pseudomonas putida & $1(10)$ & & $1(3)$ & & & \\
\hline Raoutella ornithinolytica & $1(10)$ & $4(14)$ & $5(13)$ & & & \\
\hline Staphylococcus xylosus & $3(30)$ & $1(3)$ & $4(10)$ & & & \\
\hline Streptococcus gordonii & & $1(3)$ & $1(3)$ & & & \\
\hline Staphylococcus hominis & & & & $2(14)$ & & $2(4)$ \\
\hline Total de Cepas & 10 & 29 & 39 & 14 & 31 & 45 \\
\hline № de espécies/Grupo & 4 & 9 & 11 & 6 & 7 & 8 \\
\hline Índice de Shannon-Wiener & 1,17 & 1,75 & 1,78 & 1,63 & 1,65 & 1,75 \\
\hline
\end{tabular}

Na cavidade oral da espécie $C$. jacchus juvenis as bactérias mais frequentes foram E. coli (29\%), E. cloacae (18\%), K. pneumoniae (12\%) e Serratia marcescens (6\%); enquanto que nos adultos os percentuais maiores foram para K. pneumoniae (24\%), E. cloacae (22\%), E. coli (11\%) e S. marcescens 5 (11\%). Com relação às bactérias isoladas da ampola retal nos juvenis, as espécies predominantes foram $K$. pneumoniae $(25 \%)$, E. coli $(22 \%)$, K. oxytoca $(9 \%)$ e S. xylosus (3\%); 
enquanto que nos adultos foram E. coli (39\%), K. pneumoniae (34\%) e S. xylosus (7\%). A diversidade de espécies avaliada pelo Índice de Shannon-Wiener, na cavidade oral, demonstrou diferença nas variáveis estudadas (juvenil 1,8 e adulto 1,4), sendo maior a diversidade de espécies nos juvenis. Já com relação à ampola retal, também se mostrou maior nos jovens (juvenil 1,5 e adulto 1,3), como mostrado na Tabela 2.

Tabela 2. Espécies bacterianas identificadas da cavidade oral e ampola retal de 30 indivíduos da espécie C. jacchus mantidos em cativeiro no CENP - Ananindeua/PA

\begin{tabular}{|c|c|c|c|c|c|c|}
\hline \multirow{3}{*}{ Bactérias } & \multicolumn{3}{|c|}{ Cavidade oral } & \multicolumn{3}{|c|}{ Ampola retal } \\
\hline & $\begin{array}{l}\text { Juvenis } \\
n=8\end{array}$ & $\begin{array}{l}\text { Adultos } \\
\mathrm{n}=\mathbf{2 2}\end{array}$ & Total & $\begin{array}{l}\text { Juvenis } \\
n=8\end{array}$ & $\begin{array}{l}\text { Adultos } \\
\mathrm{n}=\mathbf{2 2}\end{array}$ & Total \\
\hline & $\mathbf{N}(\%)$ & $\mathbf{N}(\%)$ & $\mathbf{N}(\%)$ & $\mathbf{N}(\%)$ & $\mathbf{N}(\%)$ & $\mathbf{N}(\%)$ \\
\hline Aeromonas salmonicida & & & & & $1(2)$ & $1(1)$ \\
\hline Aeromonas hydrophila & & & & $1(3)$ & & $1(1)$ \\
\hline Acinetobacter baumannil & $1(6)$ & $1(2)$ & $2(3)$ & & & \\
\hline Chromobacter violaceum & $1(6)$ & & $1(2)$ & & & \\
\hline Citrobacter farmeri & & & & & $1(4,5)$ & $1(1)$ \\
\hline Citrobacter freundii & & $1(2)$ & $1(2)$ & $2(6)$ & $1(4,5)$ & $3(4)$ \\
\hline Citrobacter youngae & & & & $1(3)$ & $1(4,5)$ & $2(3)$ \\
\hline Enterobacter aerogenes & $1(6)$ & $1(2)$ & $2(3)$ & $1(3)$ & $1(4,5)$ & $2(3)$ \\
\hline Enterobacter cloacae & $3(18)$ & $10(22)$ & $13(21)$ & $1(3)$ & & $1(1)$ \\
\hline Escherichia coli & $5(29)$ & $5(11)$ & $10(16)$ & $7(22)$ & $16(39)$ & $23(32)$ \\
\hline Klebsiella pneumoniae & $2(12)$ & $11(24)$ & $13(21)$ & $8(25)$ & $14(34)$ & $22(30)$ \\
\hline Klebsiella oxytoca & $1(6)$ & $2(4)$ & $3(5)$ & $3(9)$ & & $3(4)$ \\
\hline Kluyvera cryocences & & $1(2)$ & $1(2)$ & & & \\
\hline Hafnia alvei & & $1(2)$ & $1(2)$ & & & \\
\hline Pantoea spp & & $1(2)$ & $1(2)$ & & & \\
\hline Proteus mirabilis & & $2(4)$ & $2(3)$ & $1(3)$ & $2(5)$ & $3(4)$ \\
\hline Providencia alcalifaciens & & & & $2(6)$ & & $2(3)$ \\
\hline Pseudomonas putida & & & & $1(3)$ & & $1(1)$ \\
\hline Pseudomonas rettgeri & & & & $1(3)$ & & $1(1)$ \\
\hline Pseudomonas stutzeri & $1(6)$ & $2(4)$ & $3(5)$ & & & \\
\hline Raoutella ornithinolytica & & & & $1(3)$ & & $1(1)$ \\
\hline Raoutella planticola & & $2(4)$ & $2(3)$ & & $1(2)$ & $1(1)$ \\
\hline Serratia fonticola & $1(6)$ & & $1(2)$ & & & \\
\hline Serratia marcescens & $1(6)$ & $5(11)$ & $6(10)$ & $1(3)$ & & $1(1)$ \\
\hline Shigomonas paucimobilis & & $1(2)$ & $1(2)$ & & & \\
\hline Staphylococcus xylosus & & & & $1(3)$ & $3(7)$ & $4(5)$ \\
\hline Total de Cepas & 17 & 46 & 63 & 32 & 41 & 73 \\
\hline № de espécies/Grupo & 10 & 15 & 17 & 15 & 10 & 18 \\
\hline Índice de Shannon-Wiener & 1,8 & 1,4 & 1,5 & 1,5 & 1,3 & 0,9 \\
\hline
\end{tabular}

Para determinar o perfil de sensibilidade das bactérias frente aos antimicrobianos foram selecionadas as bactérias que apresentaram maiores frequências de identificação, destacando-se Citrobacter spp., Enterobacter spp., E. coli, Klebsiella spp., P. mirabilis, Pseudomonas spp., Raoutella spp. e Serratia spp..

As cepas bacterianas isoladas da cavidade oral (Figura 1) foram sensíveis à ceftazidima, cefalotina, ertapenem, meropenem, amicacina, levofloxacina, nitrofurantoína, gentamicina e sulfametoxazol/ trimetoprim. Adicionalmente, todas as bactérias apresentaram elevados percentuais de resistência à ampicilina, amoxicilina, cefalotina, cefoxitina, ácido nalidíxico e nitrofurantoína. A espécie E. coli 
apresentou elevado percentual de sensibilidade aos antibióticos analisados.

(A) Enterobacter spp. ( $\mathrm{n}=18)$

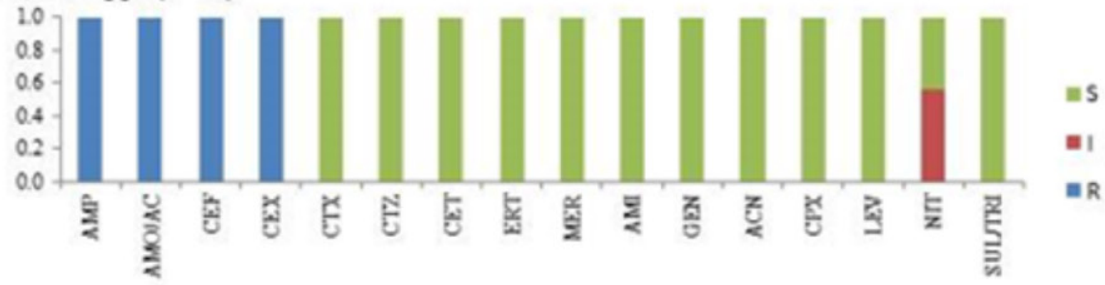

(B) Escherichia coli $(\mathrm{n}=13)$

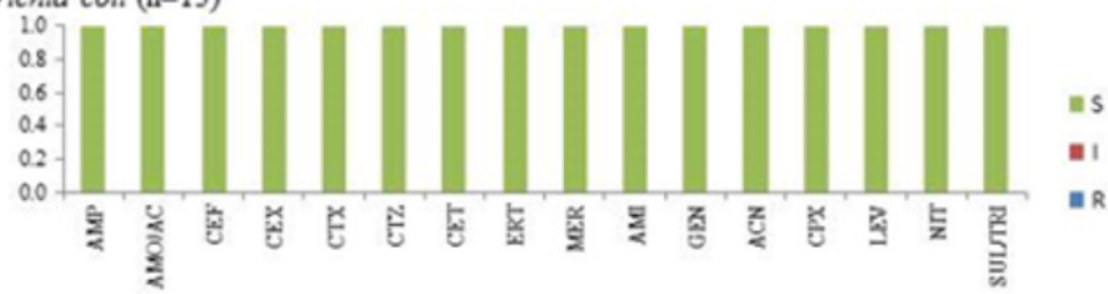

(C) Klebsiella spp. ( $\mathrm{n}=34)$

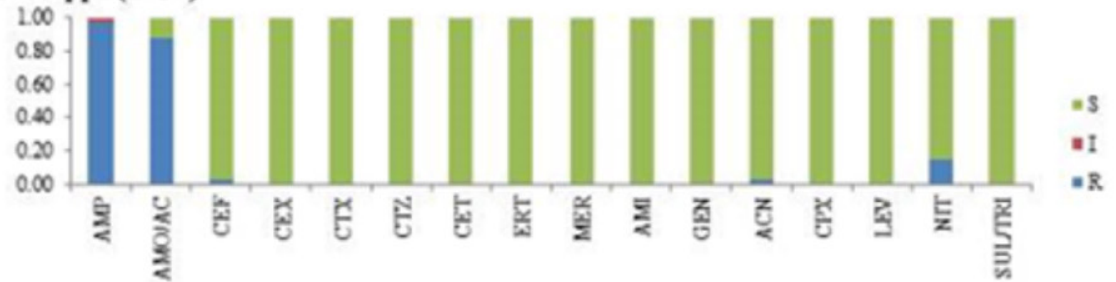

(D) Raoutella spp. ( $\mathrm{n}=7)$

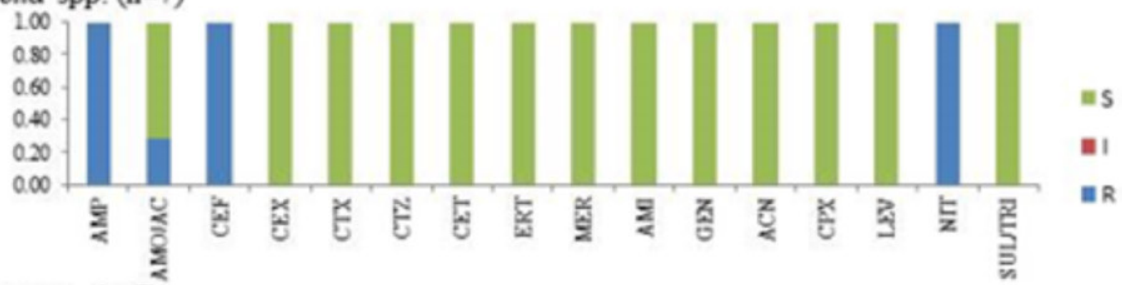

(E) Serratia spp. $(\mathrm{n}=7)$

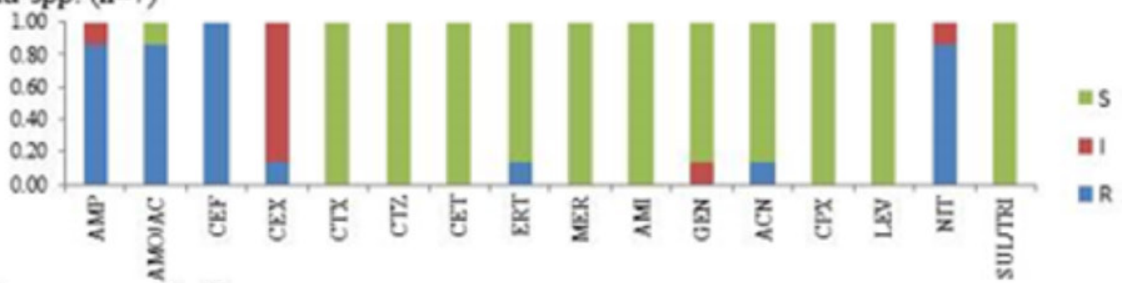

(F) Pseudomonas spp. $(\mathrm{n}=4)$

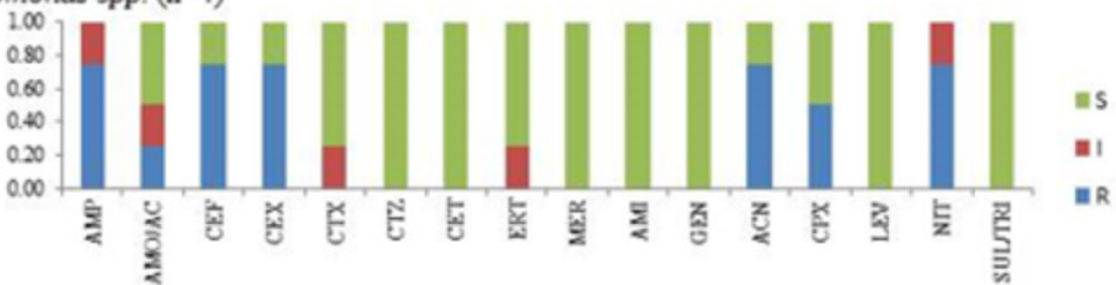

Figura 1. Perfil de sensibilidade de 16 antibióticos frente a seis espécies bacterianas da cavidade oral de $S$. collinsi e $C$. jacchus. $\mathrm{AMP}=$ ampicilina, $\mathrm{AMO} / \mathrm{AC}=$ amoxicilina/ácido clavulânico, CEF $=$ cefalotina $\mathrm{CEX}=$ cefoxitina, CTX= cefotaxima, $\mathrm{CTZ}=$ ceftazidima, $\mathrm{CET}=$ ceftriaxona, $\mathrm{ERT}=$ ertapenem, $\mathrm{MER}=$ meropenem, $\mathrm{AMI}=$ amicacina, GEN= gentamicina, $\mathrm{ACN}=$ ácido nalidixico, $\mathrm{CPX}=$ ciprofloxacina, $\mathrm{LEV}=$ levofloxacina, NIT= nitrofurantoina e $\mathrm{SUL} / \mathrm{TRI}=$ sulfametoxazol/trimetoprim, $\mathrm{S}-$ Sensível, I - Intermediário e R - Resistente. 
Com relação aos resultados do antibiograma de isolados da ampola retal (Figura 2), as espécies Citrobacter spp., Enterobacter spp. e E. coli apresentaram elevados percentuais de resistência à ampicilina, amoxicilina, cefalotina, cefoxitina, nitrofurantoína, gentamicina, ácido nalidíxico, ciprofloxacina, levofloxacina, sulfametoxazol/trimetoprim. As espécies de Klebsiella spp. apresentaram elevados percentuais de resistência à ampicilina e foram sensíveis à cefotaxima, amicacina, ácido nalidíxico, ciprofloxacina, levofloxacina e a sulfametoxazol/trimetoprim. Todas as espécies bacterianas apresentaram elevada sensibilidade à cefotaxima e amicacina.

(A) Citrobacter spp. $(\mathrm{n}=6)$

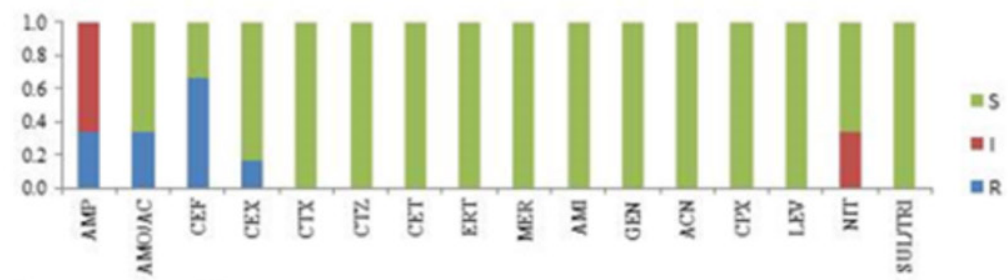

(B) Enterobacter spp. ( $\mathrm{n}=11)$

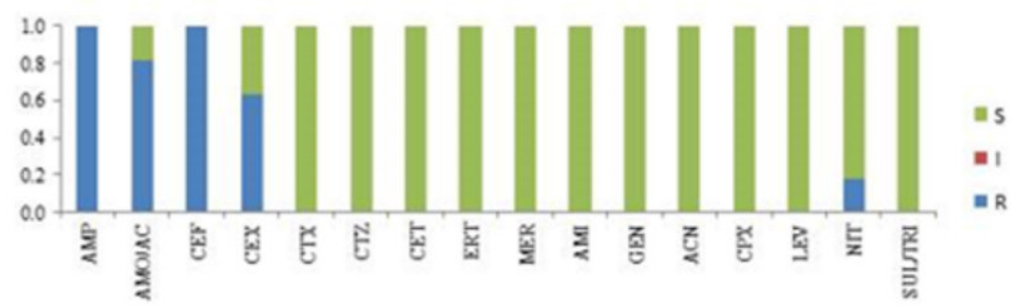

(C) Escherichia coli $(\mathrm{n}=37)$

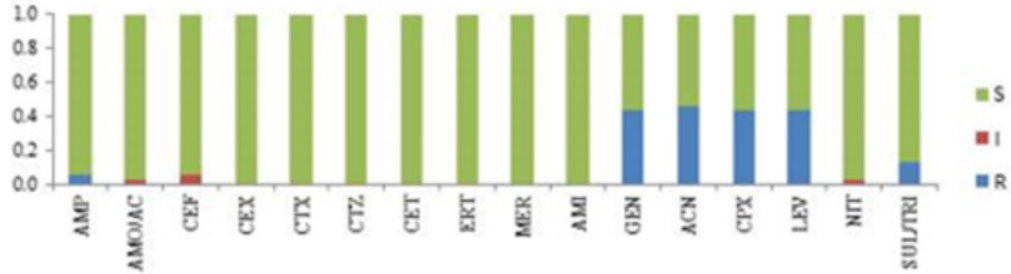

(D) Klebsiella spp. $(\mathrm{n}=41)$

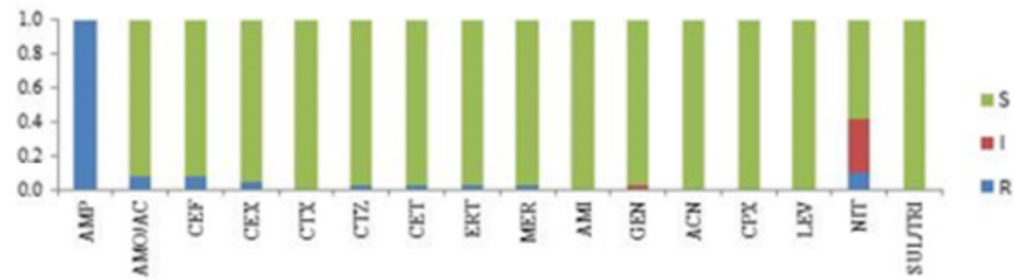

(E) Proteus mirabilis ( $\mathrm{n}=7)$

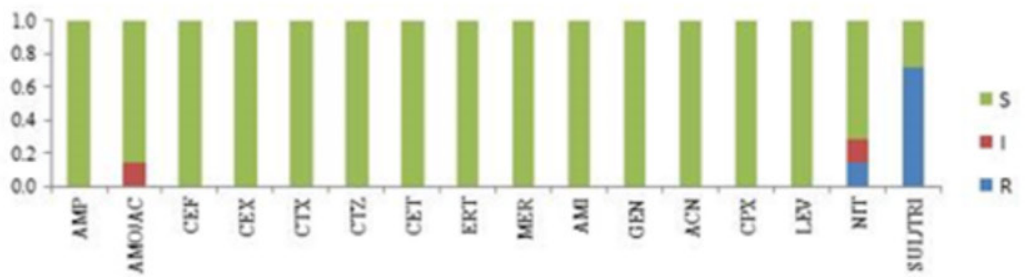

Figura 2. Perfil de sensibilidade de 16 antibióticos frente a cinco espécies bacterianas isoladas da ampola retal de $S$. collinsi e $C$. jacchus. $\mathrm{AMP}=$ ampicilina, $\mathrm{AMO} / \mathrm{AC}=$ amoxicilina/ácido clavulânico, CEF $=$ cefalotina, $\mathrm{CEX}=$ cefoxitina, $\mathrm{CTX}=$ cefotaxima, $\mathrm{CTZ}=$ ceftazidima, $\mathrm{CET}=$ ceftriaxona, $\mathrm{ERT}=$ ertapenem, $\mathrm{MER}=$ meropenem, $\mathrm{AMI}=$ amicacina, GEN= gentamicina, $\mathrm{ACN}=$ ácido nalidixico, $\mathrm{CPX}=$ ciprofloxacina, $\mathrm{LEV}=$ levofloxacina, NIT $=$ nitrofurantoina e SUL/TRI $=$ sulfametoxazol/trimetoprim, S Sensível, I - Intermediário e R - Resistente. 


\section{Discussão}

Neste estudo foram encontradas diversas espécies bacterianas, evidenciando a variação interindividual da composição bacteriana da cavidade oral e da ampola retal. Segundo Avalos-Téllezet et al. ${ }^{(11)}$, essa composição bacteriana é decorrente da interação entre o hospedeiro e o meio ambiente que estabelece a microbiota normal desses animais. A maior ocorrência foi de bactérias Gram negativas. De acordo com Brasil ${ }^{(12)}$, os 12 gêneros isolados (Aeromonas, Citrobacter, Enterobacter, Escherichia, Klebsiella, Proteus, Providencia, Pseudomonas, Raoultella, Serratia, Sphingomonas e Staphylococcus) possuem importância clínica na saúde animal e na saúde pública e podem estar associados às mais diferentes patologias nos mais diversos sítios do organismo humano e animal.

O isolamento dos gêneros Citrobacter, Enterobacter, Klebsiella e Proteus a partir da cavidade oral e da ampola retal das espécies estudadas também foi relatado por Verona ${ }^{(13)}$, que, ao analisar a cavidade oral e o ânus de saguis (C. jacchus) de vida livre no Rio de Janeiro, considerou os microrganismos isolados como bactérias comensais do trato gastrointestinal.

A análise dos dados demonstrou que E. coli e Klebsiella spp. prevaleceram nos isolados da cavidade oral e na ampola retal nas duas faixas etárias analisadas. Do mesmo modo, essas bactérias foram isoladas por Mugishaet et al. ${ }^{(14)}$ a partir da cavidade oral de chimpanzés saudáveis mantidos em um santuário Africano. Entretanto, Galera et al. ${ }^{(15)}$ isolaram Klebsiella sp. da conjuntiva ocular de macacos-prego (Sapajus apella) e macacos bugios (Alouatta caraya) sadios. A Klebsiella spp. é encontrada no intestino e na cavidade oral normal em muitos PNH, mas as infecções causadas a partir de estirpes patogênicas podem causar morbidade e mortalidade significativa nesses animais ${ }^{(8)}$. David et al. ${ }^{(16)}$ também isolaram E. coli e K. pneumoniae de amostras coletadas durante exames post-mortem de C. jacchus que apresentavam colite e também de micos (Saguinus spp.) com peritonite.

Segundo Ludlage e Mansfield ${ }^{(17)}$, E. coli é um dos principais causadores de diarreia hemorrágica em colônias de $C$. jacchus mantidos em cativeiro e a presença de carreadores assintomáticos é comum na infecção por esse microrganismo. Ainda segundo esses autores, a infecção por E. coli pode persistir por vários anos, mesmo após a realização do tratamento, sendo que a contaminação se dá pela via fecal-oral e as principais formas de introdução desse patógeno em colônias de saguis cativos são fômites contaminados e o contato com humanos ou PNH contaminados.

Através de métodos moleculares, Carvalho et al. ${ }^{(18)}$ identificaram E. coli enteropatogênica em amostras coletadas com swabs do reto e cólon de primatas neotropicais (Callithrix sp., Alouatta fusca e Saguinus fuscicollis) sem sinais clínicos de doença entérica e em animais que vieram a óbito com diarreia e/ou enterite. Esses autores sugeriram que PNH podem ser reservatórios naturais de E. coli e, portanto, representam fontes de infecção desse microrganismo para outros $\mathrm{PNH}$ e para o ser humano.

$K$. pneumoniae foi observada com maior frequência nas duas espécies estudadas, sendo que em $S$. collinsi houve diferença significativa nos isolados orais entre as variáveis juvenil e adulto. Na espécie C. jacchus, houve diferença nas variáveis da cavidade oral e retal. Em um estudo, Verona ${ }^{(13)}$ isolou $K$. pneumoniae a partir de swabs orais de C. jacchus saudáveis de vida livre e de cativeiro. Contudo, Pisharath et al. ${ }^{(19)}$ descreveram a ocorrência de septicemia e peritonite secundária à infecção por $K$. pneumoniae em seis exemplares de $C$. jacchus mantidos em cativeiro nos EUA.

O gênero Enterobacter raramente pode causar doença ${ }^{(20)}$. Neste estudo, E. aerogenese e E. cloacae estiveram presentes em ambas as espécies, sendo que $E$. cloacae apresentou maior frequência em $C$. 
jacchus. As duas espécies já foram relatadas por Zaniolo et al. ${ }^{(21)}$ em um estudo com Sapajus nigritus, ao analisarem 16 animais de vida livre.

Com relação à análise do Índice de Shannon-Wiener, verificou-se uma diferença de diversidades de espécies bacterianas encontradas em $S$. collinsi e C. jacchus, tanto na cavidade oral quanto na ampola retal. Da Silva et al. ${ }^{(22)}$, em um estudo com $A$. azarai criados em cativeiro, observaram uma maior diversidade de bactérias encontradas em machos $\left(\mathrm{H}^{\prime}=2,16\right)$ do que em fêmeas $\left(\mathrm{H}^{\prime}=1,68\right)$.

As análises dos dados demonstraram que, entre os isolamentos de bactérias Gram positivas coagulasenegativas, foram encontradas as espécies $S$. xylosus e $S$. hominis. Da Silva et al. ${ }^{(22)}$ encontraram espécies colonizando as mucosas vaginal e prepucial de macacos da noite (Aotus azarai infulatus) mantidos em cativeiro. Sobreira et al. ${ }^{(23)}$ também relataram o isolamento de espécies do gênero Staphylococcus em primatas da espécie Sapajus libidinosus de vida livre.

Segundo os autores, o tratamento com antimicrobianos e a contaminação com linhagens resistentes, associadas a humanos, são citadas como as principais causas da ocorrência de estafilococos resistentes a antibióticos em PNH em cativeiro.

Com relação ao perfil de sensibilidade e resistência dentre as bactérias isoladas da cavidade oral, observou-se que os maiores percentuais de resistência ocorreram para os antibióticos: ampicilina, amoxicilina e cefalotina, com exceção para E. coli, que apresentou elevada sensibilidade a todos os 16 antibióticos analisados. Resultados semelhantes foram encontrados por Da Silva et al. ${ }^{(22)}$ ao observarem que $E$. coli apresentou elevada sensibilidade a 17 antibióticos utilizados no estudo.

Para as bactérias isoladas da ampola retal, os isolados de Enterobacter spp. apresentaram elevados percentuais de resistência à ampicilina, amoxicilina, cefalotina, cefoxitina. Já o gênero Klebsiella apresentou elevada resistência à ampicilina, o que foi ratificado por Da Silva et al. ${ }^{(22)}$. Segundo Magiorakos et al. ${ }^{(24)}$, as bactérias resistentes a um ou mais antimicrobianos, em três ou mais classes de antimicrobianos, são definidas como multirresistentes.

\section{Conclusão}

Conclui-se que os microrganismos identificados na cavidade oral e ampola retal de $S$. collinsi e $C$. jacchus apresentaram percentuais elevados de resistência aos antibióticos utilizados no criatório. Desta forma, recomenda-se medidas de controle baseadas no monitoramento da sanidade dos animais para evitar surtos causados por espécies bacterianas patogênicas, que podem comprometer a manutenção dos animais em cativeiro, em especial PNH criticamente ameaçados de extinção.

\section{Agradecimentos}

Somos extremamente gratos ao Centro Nacional de Primatas e à Universidade Federal do Pará pela colaboração, execução e idealização desta pesquisa.

\section{Referências}

1. Abee CR. Alternative New World Primate Models for Non-AIDS Research. ILAR Journal. 2003;44:231- 
235.

2. Wright EM, Bush DE. The reproductive cycle of the Capuchin (Cebus apella). Laboratory Animal Science. 1977;27:651-654.

3.Tlaskalová-Hogenová H, Stepánková R, Hudcovic T, Tucková L, Cukrowska B, Lodinová-Zádníková R, Kozáková H, Rossmann P, Bártová J, Sokol D, Funda DP, Borovská D, Reháková Z, Sinkora J, Hofman J, Drastich P, Kokesová A. Commensal bacteria (normal microflora), mucosal immunity and chronic inflammatory and autoimmune diseases. Immunology Letter. 2004;93:97-108.

4. Sorum H, Sunde M. Resistance to antibiotics in the normal flora of animals. Veterinary Research. 2001;32:227-241.

5. Weese JS, Van Duijkeren E. Methicillin-resistant Staphylococcus aureus and Staphylococcus pseudo intermedius in veterinary medicine. Veterinary Microbiology. 2010;140:418-429.

6. Linhares IM, Giraldo PC, Baracat EC. Novos conhecimentos sobre a flora bacteriana vaginal. Revista da Associação Médica Brasileira.2010;56:370-374.

7. Round JL, Mazmanian SK. The gut microbiota shapes intestinal immune responses during health and disease. Nature Reviews Immunology. 2009;9:313-23.

8. Simmons J, Gibson S. Bacterial and mycotic diseases of nonhuman primates. In: Abee RC, Mansfield K, Tardif S, Morris T. Nonhuman Primates in Biomedical Research. 2nd ed. London: Elsevier 2012. p. 105-172.

9. Robert S, Chambers S. Diagnosis and management of Staphylococcus aureus infections of the skin and soft tissue. Internal Medicine Journal. 2005;35:97-105.

10. Menezes-Costa A, Machado-Ferreira E, Voloch CM, Bonvicino CR, Seuánez HN, Leoncini O, Soares CAG. Identification of Bacterial Infection in Neotropical Primates. Microbiology Ecology. 2013;66:471-478.

11. Avalos-Téllez R, Suárez-Güemes F, Carrillo-Casas EM, Hernández-Castro R. Bacteria and yeast normal microbiota from respiratory tract and genital area of bottlenose dolphins (Tursiopstruncatus). In: Mendez-Vilas A. Current Research, Technology and Education Topics in Applied Microbiology and Microbial Biotechnology. 2nd ed. Bandajoz: Formatex; 2010. p. 666-673.

12. Brasil. Agência Nacional de Vigilância Sanitária. Manual de microbiologia clínica para o controle de infecção em serviços de saúde. 1st ed. Brasília: Editora da Agência Nacional de Vigilância Sanitária; 2004. 9p.

13. Verona CES. Parasitos em sagui-de-tufo-branco (Callithrix jacchus) no Rio de Janeiro. Rio de Janeiro: Tese de Doutorado em Saúde Pública-Fundação Oswaldo Cruz; 2008 Oct 01 [cited 2017 abril 20]. Available from: http://bvssp.icict.fiocruz.br/pdf/25482_Veronacesd.pdf

14. Mugisha L, Köndgen S, Kaddu Mulindwa D, Gaffikin L, Leendertz FH. Nasopharyngeal colonization by potentially pathogenic bacteria found in healthy sem-captive wild-born chimpanzees in Uganda. American Journal of Primatology. 2014; 76:103-110.

15. Galera PD, Ávila MO, Ribeiro CR, SANTOS FV. 2002. Estudo da microbiota da conjuntiva ocular de macacos-pregos (Cebus apella Linnaeus, 1758) e macacos bugio (Alouatta caraya Humboldt, 1812), provenientes do reservatório de Manso-MT, Brasil. Arquivos do Instituto Biológico. 2002;69:33-36.

16. David JM, Dick JR EJ, Gene E, Hubbard B. Spontaneous pathology of the common marmoset (Callithrix jacchus) and tamarins (Saguinus oedipus, Saguinus mystax). Journal of Medical Primatology. 2009;38:347359.

17. Ludlage E, Mansfield KG. Clinical care and diseases of the common marmoset (Callithrix jacchus). 
Comparative Medicine. 2003;53:369-382.

18. Carvalho VM, Gyles CL, Ziebell K, Ribeiro MA, Catão-Dias JL, Sinhorini IL, De Castro AFP. Characterization of monkey enteropathogenic Escherichia coli (EPEC) and human typical and atypical EPEC serotype isolates from neotropical nonhuman primates. Journal of Clinical Microbiology. 2003;41:1225-1234.

19. Pisharath HR, Cooper TK, Brice AK, Cianciolo RE, Pistorio AL, Wachtman LM, Mankowski JL. Iniciante CE Septicemia e peritonite em uma colônia de Callithrix jacchus secundárias à infecção Klebsiella pneumoniae. Contemporary Topicsin Laboratory Animal Science. 2005;

20. Quinn PJ, Markeu BK, Carter NE, Donnely WJ, Leonard EC. Microbiologia veterinária e doenças infecciosas. 1st ed. Porto Alegra: Editora Artmed; 2005. 512p.

21. Zaniolo, MM, Oliveira, AF, Tramontin, RS, Santos, IC, Delai, RM, Pereira, UP, Pachaly, EMV, Pachaly, JR, Martins, LA, Gonçalves, DD. Identification of enterobacteria in free-living nonhuman primates in an urban park in the northern region of the state of Paraná, Brazil. Semina: Ciências Agrárias. 2018. 39, 31115-1124

22. Da Silva GA, Monteiro FOB, Dias HLT, Cavalcante RO, Sampaio AIF, da Conceição MEBAM, Takeshita RSC, de Castro PHG, Feijó FMC, Rahal SC. Qualitative analysis of preputial and vaginal bacterial microbiota in owl monkeys (Aotus azarai infulatus) raised in captivity. Journal of Medical Primatology. 2013;42:71-78.

23. Sobreira, EA, Braga, CASB, Rahal, SC, Ribeiro, EL, Vasconcelos, LSNO, Carneiro, LC, Teixeira, CR, Almeida, CCD, Haddad Junior,V. Oral microbiota and their antibiotic susceptibility in free-living monkeys in Goiás State, Brazil: Repercussions for injuries in humans. Revista da Sociedade Brasileira de Medicina Tropical. 2019. 52: 1-4.

24. Magiorakos A, Srinivasan A, Carey RB, Carmeli Y, Falagas ME, Giske CG, Harbarth S, Hindler JF. Multidrug-resistant, extensively drug-resistant end pandrug-resistant bactéria: an international expert proposal for interim standard definitions for acquired resistance. Clinical Microbiology and Infection. 2011;18:268-281. 